\title{
Huge Inflammatory Dentigerous Cyst: Case Report
}

Al-assaf $\mathrm{M}^{1 *}$, Al-awad A², Al-Mandily A ${ }^{1}$, Al-Khen $\mathrm{M}^{2}$, Farhoud $\mathrm{A}^{1}$

${ }^{1}$ Department of Oral Histology and Pathology, Faculty of Dentistry, Damascus University, Damascus, Syria.

${ }^{2}$ Department of Oral and Maxillofacial Surgery-General Assembly of Damascus Hospital, Damascus, Syria.

\section{Abstract}

\begin{abstract}
Dentigerous cyst could be defined as an odontogenic cyst that envelops the crown of an unerupted tooth, caused due to accumulation of fluid between the reduced enamel epithelium and the enamel surface.

This cyst is the most common odontogenic cyst of development origin comprising $20 \%$ of all jaw cysts. Most dentigerous cysts occur in the second to third decades of life with a slight male predilection.

This case report presents a case of large dentigerous cyst in a 13-year-old female. The lesion was liquid with thin border and there are three unerupted teeth extended to the whole right maxillary sinus. All the soft and hard tissues have a normal appearance with an obvious swelling and easily palpated in the upper right vestibular area.

Large dentigerous cysts are uncommon, and such lesions associated with an unerupted tooth may be odontogenic tumors like Keratocystic odontogenic tumors or unilocular ameloblastomas. Hence it is important that a diagnosis is not made on a radiographic evidence alone.
\end{abstract}

Keywords: Dentigerous Cyst; Unerupted Tooth; Odontogenic Cyst; Unilocular; Maxillary Sinus.

\section{Introduction}

Dentigerous cyst could be defined as an odontogenic cyst that envelops the crown of an unerupted tooth [1], caused due to accumulation of fluid between the reduced enamel epithelium and the enamel surface $[2,3]$.

This results in a cyst attached to the tooth at the cement-enamel junction, with the crown enclosed in its lumen [4].

This cyst is the most common odontogenic cyst of development origin comprising $20 \%$ of all jaw cysts [5].

Dentigerous cyst is always associated with a permanent tooth and is seldom seen in relation with primary a tooth and most dentigerous cysts occur in the second to third decades of life with a slight male predilection [1].

Though these cysts may be associated with any unerupted tooth, the mandibular third molars are most commonly involved, fol- lowed by the maxillary canines, maxillary third molars and mandibular second premolars [1].

Usually, dentigerous cysts are asymptomatic and are discovered during routine dental radiographic investigations [6], large dentigerous cysts may cause swelling of the jaws and may result in facial asymmetry [1].

Radiographs show a unilocular radiolucent lesion enveloping the crown of an unerupted tooth, this radiolucency has a well-defined and corticated border. The lesion may sometimes displace the involved tooth to a considerable distance and may cause root resorption of adjacent teeth [1]. Large dentigerous cysts are uncommon, and such lesions associated with an unerupted tooth may be odontogenic tumors like Keratocystic odontogenic tumors or unilocular ameloblastomas [7]. Hence it is important that a diagnosis is not made on a radiographic evidence alone.

Herein, we present a rare case report of a large dentigerous cyst in a very young female patient.

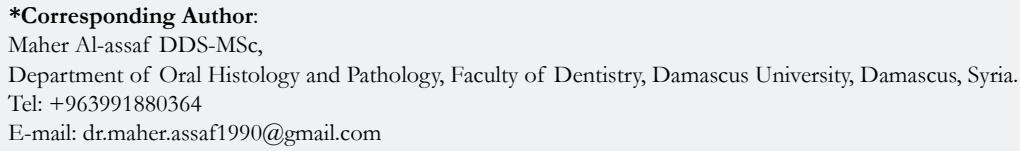

Copyright: Maher Al-assaf 2020 . This is an open-access article distributed under the terms of the Creative Commons Attribution License, which permits unrestricted use, distribution and reproduction in any medium, provided the original author and source are credited. 


\section{Case Report}

A 13-year-old female has consulted the oral and maxillofacial department because of a swelling in the zygomatic area (right side) which is contains no pain and there are no symptoms since approximetly a year with a slightly increase in size.

In the clinical examination there is a solid mass which is obvious by palpation and its located in the right zygomatic area with an obvious facial asymmetry, painless and it could be palpated intraorally and extra orally (Figure 1).

Intraoral: all the soft and hard tissues have a normal appearance with an obvious swelling and easily palpated in the upper right vestibular area, and no movement has been noticed in the adjacent teeth (Figure 2).

Radiographic examination (CT, OPG): a radiolucent lesion in the right maxilla which is extended through the whole maxillary sinus with thin, translucent and clear borders.

Surgical procedure: after the oral and endotracheal intubation and the sterilization of the working area extra and intraorally and the isolation of the surgical working area.
An anesthesia was done with vasoconstriction in an injection above the periosteum in the upper right vestibular area.

After that a flap elevation was done on the teeth adjacent to the lesion 11, 12, III, IV, V, with release incision in the frontal mesial side of 11, after that a full thickness mucoperiosteal flap was elevated until the defective vestibular bone was reached (Figure 3).

And the infected bone fragments were removed adjacent to the lesion and then the whole lesion was removed with scarping until reaching a healthy bone border.

The lesion was liquid with thin border and there are three unerupted teeth extended to the whole right maxillary sinus (Figure 4).

After that Gelfoam was inserted and the flap was repositioned and sutured using a VICRYL thread (4-0) (Figure 5).

Histologic examination: the specimen was sent for histopathological evaluation and the microscopic of all the sections revealed that hyperplastic non-keratinizedstratified squamous odontogenic epithelium surrounding the cystic cavity to be composed of cubical cells and measured about 4 to 6 cells in thickness. Connective tissue stroma showed interweaving collagen fibers, fibroblasts and vascularity. Severechronic inflammatory cells infiltration was seen in the connective tissue, revealing of inflamed dentigerous cyst

Figure 1. Pre-operative extra-oral photograph showing facial asymmetry because of right cheek swelling.

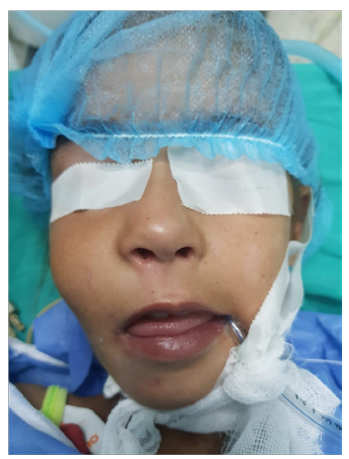

Figure 2. Pre-operative intra-oral photograph showing an obvious expansion of the buccal cortical bone.

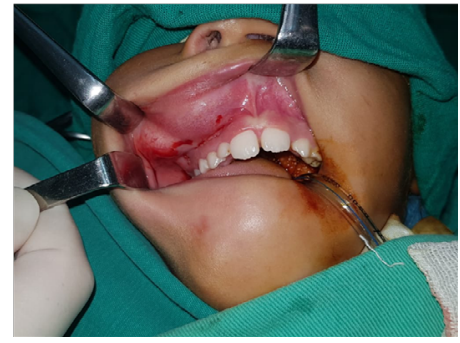

Figure 3. Intra-oral photograph showing the defective vestibular bone.

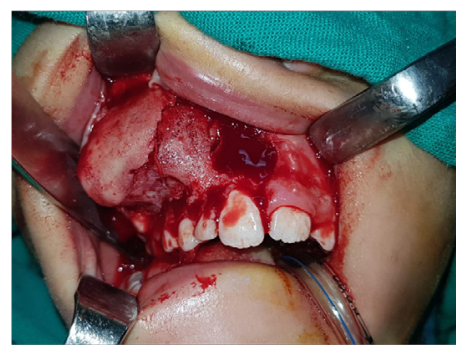


Figure 4. Post-operative view of the surgical specimens showing the complete enucleation: whole cyst with unerupted teeth.

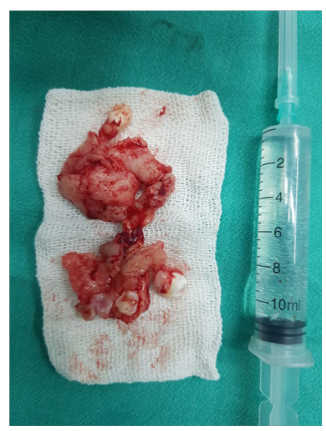

Figure 5. Completion of the surgery and wound suture.

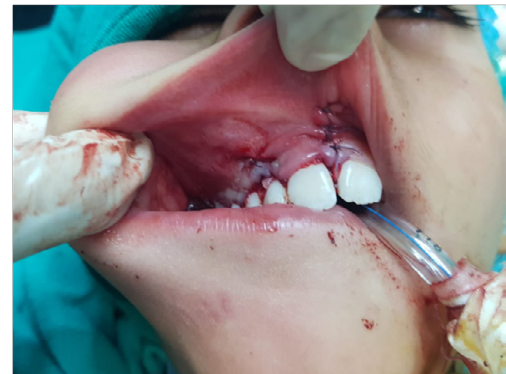

Figure 6. Histopathological photomicrograph showing the fibrous cyst wall lined with epithelium, (H\&E, magnification $40 \times)$.

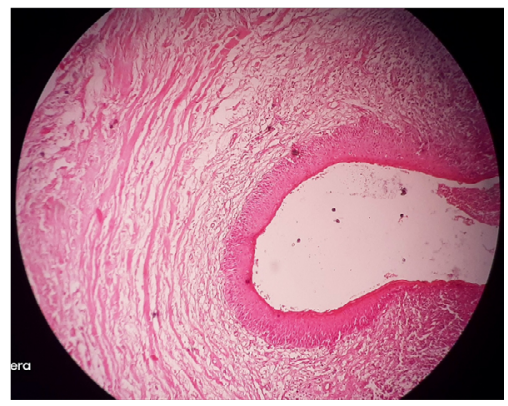

Figure 7. Histopathological photomicrograph showing: hyperplastic non-keratinized odontogenic epithelium, (H\&E, magnification $40 \times$ ).

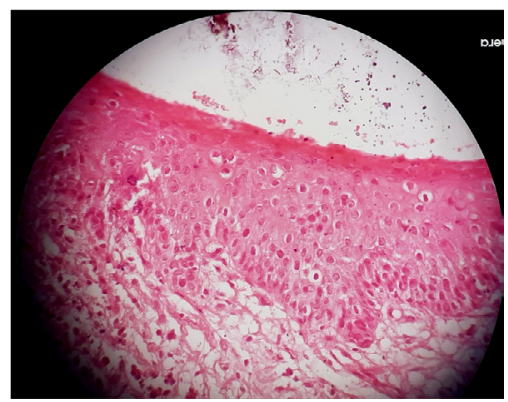

Figure 8. Histopathological photomicrograph showing: interweaving collagen fibers, severe chronic inflammatory cells, (H\&E, magnification $40 \times$ ).

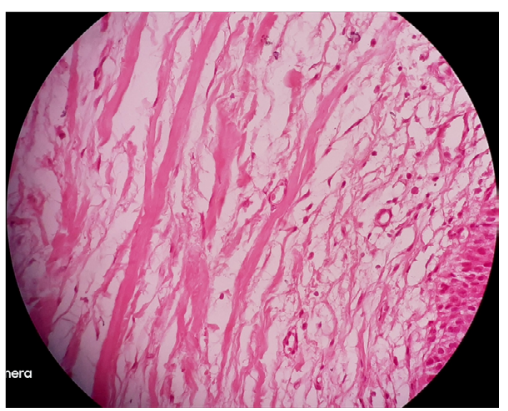


(Figure 6-7-8).

\section{Discussion}

A dentigerous cyst is benign odontogenic cyst that encloses the crown of an unerupted tooth by expansion of its follicle [5], and is attached to its cement-enamel junction, caused due to accumulation of fluid between the reduced enamel epithelium and the enamel surface $[1,5,6]$.

However, little is known as to what causes the separation of reduced enamel epithelium from the enamel allowing this accumulation of fluid [5].

The dentigerous cysts are frequently found in our practice, and potential complications that may arise from the transformation of the epithelial lining of a dentigerous cyst include ameloblastoma and squamous cell carcinoma [8-10], so it is crucial to follow-up with research to avoid complications and decide on the best treatment according to the individual case of each patient, hence, early diagnosis and treatment will increase the rate of success [11].

Also, there may be a potential for the development of an intraosseous mucoepidermoid carcinoma [12], usually derived from the mucus cells that may be present in the dentigerous cyst lining [13, 14].

In this case, a complete lesion enucleated was performed with one visit for the following reasons: 1- the site of the lesion is completely safe as there are no dangerous anatomical neighboring structures (blood vessels, nerve, etc.), 2 - the lesion had almost completely destroyed the vestibular cortex of the maxillary bone, so there is no benefit from marsupialization and the damaged bone must be removed with scraping and the damaged bone residue cannot be removed by marsupialization.

\section{Acknowledgements}

We want to declare that all laboratory works were held at the Department of oral histology and pathology, Faculty of Dentistry,
Damascus University.

\section{References}

[1]. Regezi JA, Sciubba JJ, Jordan RC. Oral Pathology: Clinical Pathologic Correlations 7th ed. St. Louis: MO, Westline Industrial Dr: Elsevier Health Sciences; 2016.

[2]. Önay Ö, Süslü AE, Yılmaz T. Huge Dentigerous Cyst in the Maxillary Sinus: A Rare Case in Childhood. Turk Arch Otorhinolaryngol. 2019 Mar:57(1):54-56. Pubmed PMID: 31049256.

[3]. Kara M, Kara Mİ, Yanık S, Altan A, Öznalçın O, Ay S. Large dentigerous cyst in the maxillary sinus leading to diplopia and nasal obstruction: case report. J Istanb Univ Fac Dent. 2015 Apr 29;49(2):46-50. Pubmed PMID: 28955536.

[4]. Demiriz L, Misir AF, Gorur DI (2015) Dentigerous cyst in a young child. Eur J Dent. 2015 Oct-Dec;9(4):599-602. Pubmed PMID: 26929702.

[5]. Shear M, Speight P. Cysts of the oral and maxillofacial regions. 4th ed. John Wiley \& Sons:Blackwell Munksgaard; 2008 Apr 15.

[6]. Neville BW, Damm DD, Allen CM, Chi AC. Oral and maxillofacial pathology.4th edn. Elsevier Health Sciences; 2015 May 13.

[7]. Kalburge JV, Latti B, Kalburge V, Kulkarni M. Neoplasms associated with dentigerous cyst: An insight into pathogenesis and clinicopathologic features. Archives of Medicine and Health Sciences. 2015 Jul 1;3(2):309.

[8]. Kondamari SK, Taneeru S, Guttikonda VR, Masabattula GK. Ameloblasto$\mathrm{ma}$ arising in the wall of dentigerous cyst: Report of a rare entity. J Oral Maxillofac Pathol. 2018 Jan;22(Suppl 1):S7-S10. Pubmed PMID: 29491596.

[9]. Gupta R, Chaudhary M, Patil S, Fating C, Hande A, Suryawanshi H. Expression of p63 in tooth germ, dentigerous cyst and ameloblastoma. J Oral Maxillofac Pathol. 2019 Jan-Apr;23(1):43-48. Pubmed PMID: 31110415.

[10]. Gay-Escoda C, Camps-Font O, López-Ramírez M, Vidal-Bel A. Primary intraosseous squamous cell carcinoma arising in dentigerous cyst: Report of 2 cases and review of the literature. J Clin Exp Dent. 2015 Dec 1;7(5):e66570.Pubmed PMID: 26644846.

[11]. Sadhwani S, Patil S, Karpe H, Rajawadha H. Lateral Dentigerous Cyst: A Case Report. IOSR-JDMS. 2019;18(4):64-67.

[12]. Li X, Wang F, Wang Y, Sun S, Yang H. An unusual case of intraosseous mucoepidermoid carcinoma of the mandible: A case report and literature review. Medicine. 2018 Dec;97(51):e13691. Pubmed PMID: 30572495.

[13]. Razavi SM, Yahyaabadi R, Khalesi S. A case of central mucoepidermoid carcinoma associated with dentigerous cyst. Dent Res J. 2017 NovDec;14(6):423-426. Pubmed PMID: 29238382.

[14]. Singh H, Yadav AK, Chand S, Singh A, Shukla B. Central mucoepidermoid carcinoma: Case report with review of literature. Natl J Maxillofac Surg. 2019 Jan-Jun;10(1):109-113. Pubmed PMID: 31205400. 